Temas del arte

DOI: $10.26807 /$ cav.vi10.295

\title{
PRECARIEDAD Y ABYECCIÓN EN WILSON PACCHA
}

\section{PRECARIOUSNESS AND ABJECTION IN WILSON PACCHA}

Franciné Córdova R.

\section{Resumen}

El presente análisis aborda la práctica artística de Wilson Paccha y su estrategia para manipular las normas del arte desde la marginalidad, insertando lo imposible de ser nombrado al arte contemporáneo del contexto quiteño, pero también me interesa hacer una crítica al proceso de abyección de Paccha, como efecto de los regímenes estéticos en "el reparto de lo sensible"1 con el modelo de lo tradicional establecido en ciertos espacios académicos, cuyo centro creó un otro que quedó por fuera, sin parte. La irrupción de un arte tocante a lo etnográfico es la contra mirada de las nuevas formas de producir arte. Paccha de formación tradicional ve en este arte la oportunidad para entrar y salir del campo artístico con su obra, pone en entre dicho la visualidad de las formas artísticas tradicionales del arte representacional, instaladas en el imaginario como las únicas formas estéticas del arte.

Palabras clave: Abyecto, norma, arte contemporáneo, abyectado, Paccha, representación, inestética.

\footnotetext{
1 "Un reparto de lo sensible fija al mismo tiempo algo común repartido y ciertas partes exclusivas" (Ranciere 2014, 19)
} 


\begin{abstract}
This analysis approach Wilson Paccha's artistic practice and his strategy to manipulate art norms from marginality, introducing the impossible of being named as contemporary art in the quiteño context. I'm also interested in criticizing Paccha's abjection process, as an effect of aesthetic regimes in " sharing of the sensitive" with themo del of the traditional established in certain academic spaces, in whose center was created an "other" that was left out. The breakup of an ethnographic study concerning art is the counter gaze of art producing new ways. Paccha sees in his art the opportunity to get in and out of the artistic field with his work, he raises doubts about the visuality of traditional forms of representational art, installed as the only aesthetic forms of art.
\end{abstract}

Keywords: Abject, norm, contemporary art, “abjected”, Paccha, representation, non-esthetic.

\title{
Biografía del autor
}

Franciné Córdova R. Licenciado en Artes Plásticas, especialidad Escultura y Grabado. Universidad Central. Maestría en Estudios del Arte en la FAUCE de la Universidad Central. Docente en la Facultad de Arquitectura, Diseño y Artes de la Pontificia Universidad Católica del Ecuador (FADA-PUCE). Dirección: Av. 12 de Octubre 1076 y Roca. Quito, Ecuador. Correo: frnachines@hotmail.com.El presente trabajo es parte de la investigación realizada para obtener grado de Maestría en Antropología Visual en la Facultad Latinoamericana de Ciencias Sociales, FLACSO-Ecuador.

\section{Introducción}

Este trabajo parte del dato de la precariedad en que vive una parte de los artistas contemporáneos en Quito. Propongo el caso de la existencia de Wilson Pacha con reflexiones teóricas acerca de la noción del abyecto en el arte contemporáneo. Se percibe una obsesión por 
lo abyecto desde el arte contemporáneo en Quito entre los años 1990 y 2010, que han permitido encontrar expresiones que dan como resultado un arte que no ha sido de fácil comprensión, difusión y consumo para el público. Lo abyecto, es aquello que causa aversión y atrae a la vez, es ambiguo, no se quiere cerca pero que se lo desea, es un objeto de deseo, que se lo excluye porque altera la vida, la identidad, pero que rompe con la realidad de lo cotidiano, lo normado por un orden de lo sensible.

En el caso de estudio, lo precario y lo abyecto ha sido un tema de interés para el campo del arte; se presenta sin decoro lo "Inmundo" Clair (2004), como postura política de lo actual, con la posibilidad de plantear la illusio de hablar del otro lado del sujeto. Considero a Wilson Paccha un artista de lo abyecto, nos presenta un arte aversivo, hace el suficiente ruido para poder acceder a los campos de poder del arte contemporáneo, él, ha visto necesario hacerle un juego a la norma, con un arte que es tocante a la sensibilidad del público del mundo del arte, lo que le valió un capital artístico que lo ha llevado a legitimarse en el campo.

La legitimación de Paccha como artista abyecto contrasta con el grado de abyección en que vive, si bien hubo un tiempo de consagración para él, en la actualidad su precariedad de vida deja ver que su estado precario lo convierten en un ser lanzado hacia el margen, un autor abyectado.

\section{Concepciones de lo abyecto.}

Butler (2009) teórica feminista y filósofa, en el texto Cuerpos que Importan, sustenta su tesis con varios textos de la teórica y filósofa Julia Kristeva, para dar a entender que la abyección en esta autora pertenece a un lugar del fuera, del botado, el que no es sujeto.

"Esta matriz excluyente mediante la cual se forman los sujetos requiere pues la producción simultanea de una esfera de seres abyectos, de aquellos que no son sujetos, pero que forman el exterior constitutivo del campo de los sujetos" (Butler, 2009, p.19).

Kristeva (1988), en su ensayo Poderes de la Perversión, hace un análisis de lo abyecto diciendo que por un lado refiere algo que no es ni sujeto ni objeto, es un algo "radicalmente excluido", que nos atrae hacia ahí, el límite, pero donde el sentido se acaba, se desploma. Por otro lado, conlleva el sentido de arrojar, expulsar. Para la autora lo abyecto connota un lanzado, 
un "arrojado al lado de lo posible y de lo tolerable, de lo pensable. Allí está, muy cerca, pero inasimilable" (Kristeva, 1988, p.7). El individuo sabe de aquel, pero al entrar en lo cultural, al orden simbólico, necesita expulsar aquello que lo amenaza.

Lo abyecto para Kristeva puede ser un estado liminal cargado de ambigüedades que subyace como proceso emocional de la estructuración de una identidad y en el proceso fisiológico de la estabilidad del cuerpo. Es ambiguo, dice, porque produce una emoción de rechazo y atracción a la vez. "Eso solicita, inquieta, fascina el deseo que sin embargo no se deja seducir. Asustado, se aparta. Repugnado, rechaza” (Kristeva, 1988, p.7).

Figari (2005) desde la psicología social, en el texto Las emociones de lo abyecto, nos dice que las emociones son un dispositivo de control y orden social que construyen a lo abyecto en la corporalidad y desde el campo del arte también se construye subjetividades de discriminación por aquello que no posee las características de un arte paradigmático, lo que motiva a que los artistas sean abyectados y puestos en precariedad.

La tesis de Figari refiere que "lo emocional es el dispositivo que en lo cotidiano y desde lo inconsciente se establece las formas instituidas de diferenciación corporal” (Figari, 2005, p.131). En esta línea, las emociones para Le Breton (1999) "No son una emanación singular del individuo sino la consecuencia íntima, en primera persona, de un aprendizaje social. [...] que nutren su sociabilidad y le señalan lo que debe sentir” (Le Breton, 1999, p.108-109).

Autoras y autores distinguen que existe una producción social de individuos abyectos que están fuera del campo de los sujetos propios de un orden simbólico normado. Así, los artistas formados hoy bajo criterios tradicionales son abyectados por la crítica en el intento por ingresar al régimen estético del arte contemporáneo, no obstante, en nuestro medio es paradójico que aun sesgos de modernismo latente operen como canon del campo actual.

"Al final de todo un siglo de supuesta critica de la tradición mimética es preciso constatar que esta tradición continúa siendo dominante hasta en las formas que se pretenden 
artística y políticamente subversivas" (Ranciere, 2010, p.54). Existen normas en nuestro medio que responden a unos intereses estéticos que benefician a cierta visualidad que no permiten una contramirada.

La contramirada, como estrategia de lo abyecto en el arte contemporáneo es aquella de la transgresión de normas que provoca repulsión, que busca descolocar, superar o completar, lo que ciertos canones no lo permiten pero que por pulsión lo desean e intentan buscar la experiencia con lo otro, lo abyecto. La ambigüedad de lo abyecto se presenta a la hora de la pulsión primaria del cual el sujeto se desconoce en sí mismo por el deseo de estar en el afuera de la norma y el deseo del abyectado por estar en el campo normado para ser reconocido.

\section{La presencia de lo abyecto en el arte contemporáneo de Quito}

De 1990 a 2000 dentro de la Facultad de Artes plásticas de Quito el arte contemporáneo aún se encontraba en ciernes, varios son los incipientes artistas que intentaban otras formas de hacer arte e iniciar una contramirada al arte objetual de la visualidad modernista, valor que le atribuía la cualidad de transmitir 'la verdad'. Cierto modelo de la mimesis nunca dejo estar presente hasta muy entrada la década del 2000 y de ser justificación necesaria para hacer del arte tradicional un modus vivendi y campo de legitimación como artista.

El predominio autoritario de ciertos docentes de aquella época determinaba sin discusiones quién era artista y lo que se definía como arte, un orden de legibilidad guiado por la estética de la buena técnica y las formas bien compuestas. German Portero estudiante de la Facultad de Artes en aquella época, nos comenta que el profesor decía: "El arte debe tener una estética, un mensaje claro, y ser lúdico"; que "para considerarse artista había que ganar tres premios: el Coloma Silva, El Mariano Aguilera, y el Premio Paris”. (Entrevista G. Portero. Septiembre 2018).

Un modo de ver -al configurar una forma de mirar- regula, marca límites hacia dentro, habilita qué se ve, y, a su vez, esconde, niega, tranquea, tabuiza. [...] Aquello que cada época considera verosímil respecto a lo visible conforma un modo de ver determinado. 
Lo verosímil [...] entra en una relación recíproca con el régimen escópico, ya que este habilitaría qué imágenes pueden reconocerse como verdaderas en una sociedad dada. Hablamos entonces de la normalización de un modo de mirar y de objetos a mirar en una cultura (Chao, 2015, p.2).

El contexto artístico para ese entonces, comenzó a activarse con otras miradas venidas del exterior (Guadalupe Álvarez, Juan Ormaza, Kevin Power)², que se vieron en la necesidad de poner su atención más en lo que está prohibido por la norma modernista, a lo que no se quiere re-pensar, ni re-ver pero que la cultura dominante la abstrae por medio de alienaciones supraculturalistas. En su ensayo curatorial para la muestra "Poéticas del borde", Álvarez (1997) crítica e historiadora de arte cubana, indica que para aquella década algunas manifestaciones artísticas comienzan a demarcarse de formas tradicionales legitimadas en la modernidad (Álvarez en Jaramillo, 2014, p.24).

El desarrollo del arte contemporáneo en Quito presenta al borde, a lo abyecto y excluido como una declaración inestética de producción de verdad político social, frente a una estética ficcional desgastada ornamental y de contemplación. Lo abyecto, será la declaración política de una inestética contemporanea contra el discurso aséptico local moderno. Varios han sido los autores que conceptualizan el arte contemporáneo como la escena que presenta a lo repulsivo de lo corporal y de lo social, algunas acepciones, manejan una perspectiva que lo ponen del lado obscuro y degradante del ser humano, que transgrede la estética del modernismo, reacción que también se da en lo local pero su efecto es más histriónico y dramático. Así, de manera general Giorgio Agamben (2011), define como contemporáneo

Aquel que tiene la mirada fija en su tiempo, para percibir no las luces, sino la oscuridad. Todos los tiempos son, para quien experimenta su contemporaneidad, oscuros. Contemporáneo es, justamente aquel que sabe ver esa oscuridad, aquel que está en condiciones de escribir humedeciendo la pluma en la tiniebla del presente (Agamben, 2011, p.21).

\footnotetext{
${ }^{2}$ Lupe Álvarez, Historiadora del Arte, critica y curadora de arte contemporanea, dicto talleres teóricos en Quito PUCE en 1993. Juan Ormaza, Docente de Arte en EE.UU, dictó talleres de arte contemporáneo, en Ilades en 2006. Kevin Power, crítico de Arte y curador de Arte contemporáneo, dictó conferencia en FLACSO en 1995. (Entrevista a Jenny Jaramillo, estudiante de Artes plásticas de la Universidad Central en $\operatorname{los} 90 \mathrm{~s})$.
} 
Dentro del arte contemporáneo, las imágenes de los artistas de Quito permiten inferir la tesis de que lo abyecto en su mayoría atiende a lo repulsivo en la corporalidad, al contexto marginal, a la clase social precarizada, "Perversidad. Está claro, vivimos en un mundo de brechas cada vez más insalvables, [...] Todo exceso produce perversidad y frente a la miseria humana que es su desecho, aparece ahora el arte llamado contemporáneo" (Viteri en Revista COCISOH-USFQ, 2017, p.26). Para Viteri el arte contemporáneo debe manejarse con cautela para no irse a los extremos, es decir, debe conservar algo de lo moderno, mientras que Guash va más allá y dice que no es raro que el arte contemporáneo sea dificultoso de entenderlo, para esto hay que mirar y reflexionar sesudamente, para entenderlo y evitar que se caiga en ideas superficiales (Guash en Hakim, 2012, p.17).

La presencia de lo abyecto en el arte contemporáneo del medio quiteño obedece a ese deseo de presentar lo aversivo, lo que poco se ve y presenta en la esfera del arte local, el testimonio de vida, del artista quiteño Wilson Paccha, egresado de la Escuela de Artes Plásticas de la Facultad de Artes, presenta desde la marginalidad del Comité del Pueblo una mirada etnográfica del ethos de su barrio. Paccha subvierte las normas de la buena estética racional por medio de la transgresión, llevando sus registros del plano de lo erótico, a la dimensión de lo porno-artístico con los soportes de la pintura. Los personajes de sus pinturas son del encuentro en su barrio; la intención es lograr una agencia, nombra y edifica lo que no tiene representación, desde la actitud inestética.

Hablar de un arte pre-humano, es decir de la posibilidad de un arte que ya no se dirigiría a lo que, en el hombre constituye su bios -su vida inteligente y reflexiva que le distingue entre todos los primates-, sino más bien... a la vida como zoe, la vida desnuda, el aquí abajo biológico, que le conduce en efecto a la zoología de las criaturas organizadas, pero también de los seres alógicos, aloga, animales privados de logos (Clair, 2004, p.21).

Pintar lo pre-humano genera un llamado de atención politico a las miradas del círculo dominante del arte, Paccha desde la marginalidad desentiende la norma que lo ha abyectado porque pinta lo obsceno, para provocar a un público decoroso que no permite que se mancille su estética contemplativa, le apunta a la illusio de trabajar desde el borde, hace ruido con lo 
abyecto para permear ese campo del poder y lograr su capital simbólico de legitimación.

"Benditas sean todas esas viejas locas conservadoras y menopáusicas; esos curadores, jurados, críticos descontinuados y timoratos que son como el perro del hortelano: "ni comen ni dejan comer” (Pacha, 2010, p.25).

\section{Abyectado: La Actitud inestética ${ }^{3}$ de Paccha}

La actitud inestética de Paccha está marcada por ciertos regímenes que se instauran en las instituciones oficiales como campos del poder, cuyo deber bajo ciertas normas es comunicar la "verdad", sin embargo y de manera sutil estas instituciones han rechazado las posibles formas y experiencias de hacer el arte en lo contemporáneo y más cuando se cruzan con los intereses de la ciencia social.

Las prácticas artísticas de Paccha obedecen a unas estrategias astutas de barriobajero marginal, su perfil de "terrorista”, como él se declara, tiene orígenes construidos desde el trabajo infantil monetizado junto a su familia nuclear, sin embargo, no se puede decir lo mismo de su contexto que a vox populi era un barrio "alarmante" infestado por una sociedad cuyos antecedentes subrayaban en los delitos punibles, El Comité del Pueblo. Barrio que, según Zapata (2007) nos cuenta, “es una ciudad satélite al norte de Quito, bastión popular con un historial violento y delictivo, caracterizado por su densidad poblacional, su caótica configuración urbanística, su estridencia visual y auditiva” (Zapata,2007, p.12).

Paccha, al ingresar a la Facultad de Artes lo ve como un espacio para regenerarse, pronto observa que es un mundo donde las clases sociales se marcan con tesón, al sentirse parte de una

\footnotetext{
${ }^{3}$ Badiou dice; "Por "inestética" entiendo una relación de la filosofía con el arte que, al mantener que el arte es en sí mismo un productor de verdades, no trata de convertir el arte en objeto para la filosofía. Frente a la especulación estética, la inestética describe los estrictos efectos intrafilosóficos producidos por la existencia independiente de algunas obras de arte. (Badiou 2009, 43). García alude al concepto y dice que la inestética va por esa capacidad de nombrar los imposibles, es esta la actitud y postura del Arte contemporáneo (García 2010, 11).
} 
clase, barriobajero, se identificará con otros de su misma laya, En el cumplimiento por las tareas académicas de las artes plásticas, mira en el dibujo, la pintura, el grabado, la manera de narrar el ethos de su barrio. Las influencias de citas externas marcan a Paccha y descubre que auto referenciarse desde su contexto es detentar lo artístico.

Esa vitalidad es resultado directo de la influencia cada vez mayor que empezó a ejercer mi entorno social sobre mi obra. Las calles, los personajes de mi barrio El Comité del Pueblo, los colores y conflictos propios de un barrio obrero, fueron impregnándose en mi pincel, con lo cual mi obra adquirió un sentido nuevo, mucho más profundo (Entrevista a W. Pacha, noviembre 2017).

Paccha, transgrede los tabúes y normas del buen comportamiento artístico de las cosas bonitas relamidas, de los padrinazgos y complicidades en los premios, rompe el silencio para develar verdades que estaban estancos tras unos órdenes culturales de visualidad que no permiten la perversión de una estética instalada en el medio quiteño. "Su pintura procaz [...] logra actualizar lo feo, convirtiendo su visión antropomórfica en el centro desde donde el artista lanza embates a nuestros pudores" (Ampuero, 2008, p.43).

Censurado Paccha de algunas instituciones por su práctica artística, insistió de todas maneras para que su obra sea aceptada en el campo. Su práctica pictórica no se ve diezmada y empieza por armar un damero para ver que fichas son las que tiene que mover para dominar el campo de juego; se relaciona con personajes que asisten a eventos artísticos con el fin de "codearse" con la elite cultural para mostrar su obra y en alguna oportunidad influir y obtener el espacio para exhibirla, invita a reuniones sociales a críticos, curadores, para asesorarse sobre lo que acontece en el campo del arte actual y a la vez para saber sobre jurados, premios, y artistas que están a la vanguardia.

$\mathrm{Al}$ conocer personas del ámbito institucional de la cultura, Paccha, aplica las lecciones de economía doméstica heredadas de su oficio de panadero y de los trueques de banda, lo que le interesa es vender y visibilizarse con su trabajo, pero ahora con la divisa de artista. Con las relaciones obtenidas del ámbito cultural, permea información clasificada sobre quien puede estar ganando cierto premio o Salón de arte o quién es rechazado. 
Aquí hay los acomodes, el que más lame avanza, el que se hace panita del panita y así, e incluso panita de los críticos, daría nombres porque los hay, pero tengo respeto porque son panas que quiero mucho, aquí hay tantos amarres en la cultura, estoy seguro que hay, existen muchos premios pero siempre se sabe a quién se va a dar (Entrevista a W. Paccha, 2019).

Así como lo enunciara Butler (2009), que hay individuos que están por fuera de la norma, que no son sujetos, que habitan un territorio por fuera de los limites, que intentan romper con el marco constituido por los sujetos, de la misma forma hay artistas que se encuentran por fuera del campo del arte que buscan la manera de inscribirse en el campo a partir de un capital social. Lo abyecto, lo rechazado, "no gozan de la jerarquía de los sujetos, pero cuya condición de vivir bajo el signo de lo "invisible" es necesaria para circunscribir la esfera de los sujetos" (Butler, 2009, p.19-20).

Paccha es una artista que ha basado su estrategia de reconocimiento con acto suspicaz, su talento para entrar y salir del campo imponiendo sus propias reglas, su propia mirada, le otorgan una habilidad performatica, salir y entrar del margen y no dejarse seducir por los objetos del deseo y modelos alienantes, le permiten analizar desde lejos lo que está en el juego del arte contemporáneo. Su mirada en el arte y en la marginalidad de lo abyectado presenta acontecimientos provocadores, elementos bizarros, esperpentos lascivos, que descolocan a la mirada más entendida. 


\section{La obra abyecta de Paccha: provocación para entrar y salir del campo artístico}

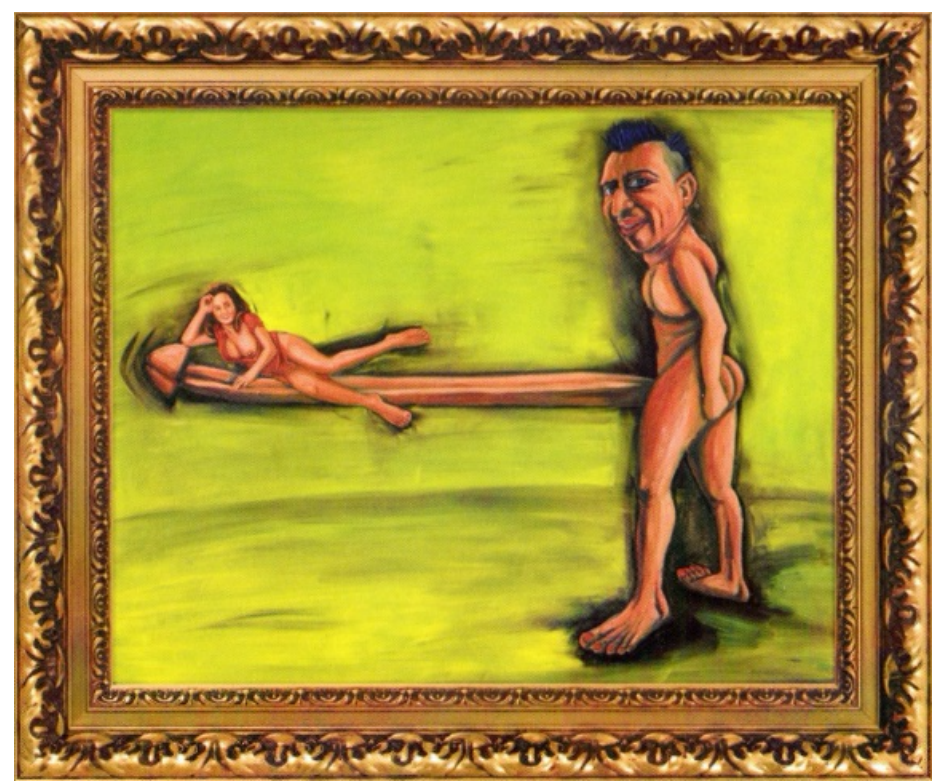

Figura 1. La mujer más pequeña del mundo (de la serie Records Guinness). Fotografía de Danilo Vallejo 2007.

La estrategia de Paccha es provocar desde su condición de abyectado, donde todo lo imposible ocurre y se nombra sin censura. En su obra, se es llevado con la pulsión de la concupiscencia, donde la carne asoma viva al deseo venal y la norma se rompe, Al final de todo un siglo de supuesta crítica de la tradición mimética es preciso constatar que esta tradición continúa siendo dominante hasta en las formas que se pretenden artística y políticamente subversivas, es el lugar de la anomia, de la nuda vida, donde los sujetos no son, pero es el territorio del deseo. Paccha, autorretratado, presenta el lado que casi no se ve del sujeto.

Así, en la obra La mujer más pequeña del mundo (figura 1), la primera impresión es como la composición altera la lectura normada de izquierda a derecha, Paccha altera el significado convencional y lo que está a diestra le da un giro a la siniestra, es decir, pasa de la derecha que pertenece a la norma a la izquierda que se remite a lo a-normado. 
Desde el psicoanálisis de Rodríguez Kauth la siniestra, connota lo bajo. Existen culturas donde la mano izquierda está reservada para menesteres indignos, que realizar actos de zurdo se considera una anormalidad y una sospecha axiológicamente desfavorable, lo siniestro se

considera moralmente negativo Kauth (2001). Paccha, registra lo que es imposible, lo obsceno llevado a la izquierda.

La distribución de los signos del cuadro aparece en una alusiva y marcada distinción de géneros, que logra indignar posiblemente a una feminista o a mujeres de buen recato. Paccha autorretratado deforme como macho sadeano, con gesto facial irónico, pone a una mujer en violento goce, donde la autoridad del falo domina y tensiona con la diminutez del goce fémino.

En este cuadro de lo absurdo Paccha juega a las muñecas, minimiza el cuerpo de la mujer, la infantiliza y nos lleva a esa dimensión de la abreacción, donde solo las mujeres jugaban con las muñecas, mundos escindidos y normados por los discursos impuestos a los sexos. Para Bajtín la hiperbolización de los cuerpos pertenece al mundo de lo grotesco, "ignora la superficie sin falla que cierra y delimita el cuerpo como acabado, [...] se interesa por lo que sale, hace brotar, se desborda del cuerpo, todo lo que busca escapar de él” (Bajtín, 1994, p.286). Paccha transgrede al campo del poder normado heterosexual con una manera bizarra y grotesca de relación en la que el goce erótico de lo sexual es de otro orden, incluso sacrificial, que viene del fuera, del cuerpo-carne sensible, de los humores y fluidos abyectos hacia el interior, lo inyecto.

\section{Referencias}

Agamben, G. (2011). Desnudez. Buenos Aires: Ediciones Adriana Hidalgo.

Ampuero, M. (2008). Paccha pintor lumpen, Revista Mundo DINERS. Sección Galería. Dinediciones.

Badiou, A. (2009). Pequeño Tratado de Inestética. Buenos Aires-Argentina. Ed. Prometeo. 
Bajtin, M. (1994). La Cultura Popular en la Edad Media y en el Renacimiento: el contexto de François Rabelais. Buenos Aires. Ed. Alianza Estudio.

Butler, J. (2009). Cuerpos que Importan: sobre los límites materiales y discursivos del "sexo". Paidós, Buenos Aires.

Clair, J. (2004). De IMMUNDO. Apofatismo y apocatástasis en el arte de hoy. ARENA Libros. España.

Chao, D. (2015). Régimen escópico e imaginario social. Revista Afuera, Estudios de Crítica Cultural. Año VI Número 11 www.revistaafuera.com.

Figari, C. (2005). Cuerpos, subjetividades y conflictos: hacia una sociología / Carlos Figari; compilado por Carlos Figari y Adrián Scribano. -1a ed.- Buenos Aires: Fundación Centro de Integración, Comunicación, Cultura y Sociedad.

García, W. (2010). La actitud inestética como condición para pensar en un arte político. Congresos Científicos de la Universidad de Murcia, XLVII Congreso de Filosofía Joven.

Hakim, C. (2012). Conceptos de arte contemporáneo. Nc-arte, compilación apoyada por la Fundación Neme. Bogotá Colombia.

Jaramillo, J. (2014). Medio artístico, trayectoria profesional y performático. Tesis de maestría en Antropología Visual Flacso.

Kauth, A. (2001). Izquierda y derecha en política. Realidad. Revista de Ciencias Sociales y Humanidades. Julio-agosto. Nro 82.

Kristeva, J. (1988). Poderes de Perversión. Siglo XXI Editores. México.

Le Breton, D. (1999), Las Pasiones Ordinarias. Antropología de las emociones. Buenos Aires. Ed. Nueva Visión SAIC. 
Pacha, W. (2010). Mi pasión por el rojo. Trabajo previo a la Licenciatura en Artes.

Especialización en Pintura y Grabado. Universidad Central del Ecuador UCE, 2010.

Ranciere, J. (2010). El espectador emancipado. Buenos Aires, Argentina. Manantial.

Ranciere, J. (2014). El Reparto de lo Sensible: estética y política. Buenos Aires, Argentina. Prometeo

Viteri, E. (2017). Cumbre Borrascosas del Arte y el Mercado. Ensayo para Revista de divulgación artística. COCISOH-USFQ. No. 3. Líneas de Expresión.

Zapata, C. (2007). PIEL DE NAVAJA. Catálogo de exposición. Cuenca Ecuador. Ed. C. Zapata

Entrevistas

Portero, G. (septiembre 2018). Egresado de la Facultad de Arte de la UCE en los 90s Pacha, W. (noviembre 2017). Egresado de la Facultad de Artes de la UCE en los 90s

Enviado: 2019-12-09

Aceptado: 2020-12-11 